\title{
AIR POLLUTION AND THE IMPACT ON ECONOMY AND HEALTH
}

\section{PhD Fatmir Emurllai}

\author{
Faculty of Contemporary Science and Technologies, South East European University, Tetovo, Republik of \\ North Macedonia \\ Institute for Environment and Health \\ E-mail: Fe26925@ seeu.edu.mk
}

\begin{abstract}
This scientific work has to do with environmental pollution in general but especially environmental air pollution. From the data of the World Health Organization are a large number of diseases that appear, are affected or exacerbated by the impact of environmental air pollution and thus affects the quality of life of people in general. Environmental pollution usually includes air, land and water pollution. Sources of pollution are usually household appliances with the use of combustible materials, vehicles which, with the materials they use for combustion, greatly pollute the environment, indiscriminate use of pesticides and chemicals in agriculture as well as waste incineration and mismanagement. The use of natural resources outside the normal criteria has had alarming effects on the environment. Environmental pollution with special emphasis on air pollution treated in this paper certainly has a significant impact on the economies of countries facing this phenomenon. Environmental policies and instruments usually tend to reduce pollution levels to reduce costs from countries' budgets as well as the impact of pollution that has gross domestic product. During pollution, of course, there are restrictions on the lives of citizens with chronic diseases, thus being absent from work and affecting the functionality of certain institutions but also various private companies.
\end{abstract}

The treatment in this paper of environmental pollutants, the impact on public health and the impact on the general economy will be more detailed.

Keywords: source of environmental pollution, environmental protection, World Health Organization, health impact, respiratory diseases, pollutants, waste mismanagement

\section{Introduction}

Air pollution is one of the most serious environmental risks. The most recent Global Burden of Disease (GBD) study estimates that air pollution - indoor and outdoor combined - was the cause of 5.5 million premature deaths globally in 2013. Air pollution also has further consequences on human health, leading in particular to an increasing number of respiratory and cardiovascular diseases. Moreover, it affects crop yields and the environment, with impacts on biodiversity and ecosystems, amongst others. These impacts have significant economic consequences, which will affect economic growth as well as welfare. The projected increase in concentrations of PM2.5 and ozone will in turn lead to substantial effects on the economy. According to the calculations in this report, global air pollution-related healthcare costs are projected to increase from USD 21 billion (using constant 2010 USD and PPP exchange rates) in 2015 to USD 176 billion 2005 in 2060. By 2060, the annual number of lost working days, which affect labor productivity, are projected to reach 3.7 billion (currently around 1.2 billion) at the global level. The market impacts of outdoor air pollution, which include impacts on labor productivity, health expenditures and agricultural crop yields, are projected to lead to global economic costs that gradually increase to $1 \%$ of global GDP by 2060 . The most dangerous consequences from outdoor air pollution are related to the number of premature deaths. This report projects an increase in the number of premature deaths due to outdoor air pollution from approximately 3 million people in 2010, in line with the latest Global Burden of Disease estimates, to 6-9 million annually in 2060. A large number of deaths occur in densely populated regions with high concentrations of PM2.5 and ozone, especially China and India, and in regions with aging populations, such as China and Eastern Europe. 
The potential economic consequences of both the market and non-market impacts of outdoor air pollution are very significant and underscore the need for strong policy action. ${ }^{1}$

In 2015, WHO and OECD estimated that the economic cost of premature death and disability from air pollution in Europe is close to USD 1.6 trillion. Air pollution takes its toll on the economy in several ways: it costs human lives, it reduces people's ability to work, it affects vital products like food, it damages cultural and historical monuments, it reduces the ability of ecosystems to perform functions societies need and it costs money in remediation or restoration. ${ }^{2}$

1"OECD POLICY HIGHLIGHTS The economic consequences of outdoor air pollution"

https://read.oecd-ilibrary.org/environment/the-economic-consequences-of-outdoor-airpollution 9789264257474-en\#page20

2"Air pollution and economic development, The United Nations Economic Commission for Europe (UNECE)" https://www.unece.org/environmental-policy/conventions/envlrtapwelcome/cross-sectorallinkages/air-pollution-and-economic-development.html

The three different market impacts of air pollution are: reduced labor productivity; increased health expenditures; and crop yield losses. They all contribute to a projection of GDP that is below the projection that excludes the pollution feedbacks on the economy. At the global level, the consequences of labor productivity and health expenditure impacts continue to increase significantly relative to GDP. In contrast, agricultural impacts are relatively stable over time in percentage of GDP, i.e., in absolute terms these impacts grow more or less at the same speed as GDP. Taken together, the total annual market costs of outdoor air pollution are projected to rise from $0.3 \%$ in 2015 to $1.0 \%$ by 2060 .

For most air pollutants, emissions are projected to increase in the coming decades. Rising emissions reflect the underlying baseline assumptions on economic growth: with increasing GDP and energy demand, especially in fast growing economies such as India and China, emissions of air pollutants rise, albeit at a slower pace than GDP. In particular, emissions of nitrogen oxides (NOx) and ammonia (NH3) are projected to increase strongly. These large changes are due to the projected increase in the demand for agricultural products and energy. In many places, concentrations of PM2.5 and ozone are already well above the levels recommended by the WHO Air quality guidelines.

The most worrying and striking impact of air pollution is the large number of premature deaths. The number of premature deaths due to outdoor air pollution is projected to increase from 3 million people globally in 2010 to a global total of 6 to 9 million people in 2060. This large increase is not only due to higher concentrations of PM2.5 and ozone, but also to an increasing and aging population and to urbanization, which leads to higher exposure.

The projected increasing concentrations of PM2.5 and ozone will also lead to a higher number of cases of illness, which will imply more hospital admissions, health expenditures and sick or restricted activity days, which lead to labor productivity losses (Table 1).

The number of cases of bronchitis is projected to increase substantially, going from 12 to 36 million new cases per year for children aged 6 to 12, and from 3.5 to 10 million cases for adults. Children are also affected by asthma, with an increasing number of asthma symptom days for children of age 5 to 19 . These increasing cases of illness have been translated into an equivalent number of hospital admissions, which are projected to increase from 3.6 in 2010 to 11 million in $2060 .^{3}$

3" OECD POLICY HIGHLIGHTS The economic consequences of outdoor airpollution”,

https://www.oecd.org/environment/indicators-modelling-outlooks/Policy-Highlights-Economic-consequencesof-outdoor-air-pollution-web.pdf 
ISSN 2661-2666 (Online) International Scientific Journal Monte (ISJM) DOI: 10.33807/monte.202004661

Volume 2. No. 1 (2019): April

The additional cases of illness also lead to an impact on normal work activities. In 2060, lost working days at the global level are projected to be around 3.75 billion days. But there will also be an increasing number of (minor) restricted activity days. ${ }^{4}$

Table 1. Projected health impacts at global level

\begin{tabular}{|l|l|l|}
\hline & 2010 & 2016 \\
\hline Respiratory disease (million number of cases) & 12 & 36 \\
\hline Bronchitis in children aged 6 to 12 & & 10 \\
\hline Chronic bronchitis (adults, cases) & 4 & \\
\hline Asthma symptom days (million number of days) & & \\
\hline Asthma symptom days (children aged 5 to 19) & 118 & 360 \\
\hline Healthcare costs (million number of admissions) & & \\
\hline Hospital admissions & & \\
\hline Restricted activity days & 4 & 11 \\
\hline Minor restricted activity days (asthma symptom days & 630 & 2580 \\
\hline Lost working days & 4900 \\
\hline & & \\
\hline & & \\
\hline & & \\
\hline
\end{tabular}

Source: OECD POLICY HIGHLIGHTS The economic consequences of outdoor air pollution 
4" OECD POLICY HIGHLIGHTS The economic consequences of outdoor air pollution”,

https://www.oecd.org/environment/indicators-modelling-outlooks/Policy-Highlights-Economic-consequencesof-outdoor-air-pollution-web.pdf

There are two major policy implications from these findings. The first is that more stringent air quality regulations could be warranted based solely on economic grounds. This is because the large economic benefits from pollution reduction are greater than previously thought and compare with relatively small abatement costs: for example, reducing emissions of fine particulates by $25 \%$ across Europe would cost EUR 1.2 billion annually according to the European Commission, but the economic benefits from such emissions reductions would be at least two orders of magnitude greater. Consequently, such a reduction in pollution would easily pass a cost-benefit test, even ignoring the large benefits in terms of avoided mortality. Secondly, air pollution control policies may contribute positively to economic growth, reinforcing the case for integrating green considerations into mainstream economic policymaking. Simulations suggest that reaching the air quality targets required by the European Commission Ambient Air Quality Directives for the period 2010-20 would increase European GDP by 1.25\%, with the most polluted countries experiencing GDP growth of up to 3\%. Since Eastern European countries face higher pollution levels on average, air pollution control policies could significantly contribute to economic convergence between Eastern and Western Europe, and could be seen as useful complements to structural policies aiming at fostering economic growth. However, poor air quality may cause direct reductions in economic activity because it negatively impacts cognitive or physical ability. In addition to impacts of pollution that are mediated through the labor market, air pollution may also have a direct impact on output, in particular in the agricultural or forestry sectors, where air pollution has the potential to damage crops or trees and thus cause reductions infield. Estimating the potential effect of pollution on high-skill workers is more challenging, because tasks are typically less routinized and can often be shifted in time and space. Nevertheless, there is some evidence that pollution also affects productivity in high skill tasks. ${ }^{5}$

Greenpeace Southeast Asia and the Centre for Research on Energy and Clean Air have released a new report about the costs of air pollution from fossil fuels, both human and economic. Burning gas, coal and oil results in three times as many deaths as road traffic accidents worldwide and it is estimated that air pollution has a $\$ 2.9$ trillion economic cost, equating to 3.3 percent of the world's GDP. In 2018, the report estimates that it was linked to 4.5 million deaths with PM2.5 pollution also responsible for 1.8 billion days of work absence, 4 million new cases of child asthma and 2 million preterm births. It can have an impact on the economy in many forms such as higher rates of asthma, diabetes or chronic respiratory diseases leading to reduced ability to work and lower participation rates in the labor force. ${ }^{6}$

5"The economic cost of air pollution: Evidence from Europe",

https://www.oecd-ilibrary.org/docserver/56119490-

en.pdf?expires=1587927668\&id=id\&accname=guest \&checksum=470CEB7142676B44CD4B93224F604411

6"This is the global economic cost of air pollution", https://www.weforum.org/agenda/2020/02/the-economicburden-of-air-pollution/

Children susceptible to asthma attacks also miss school days, impacting their learning while healthcare requirements can result in their guardians also taking extra time off work. According to the report, disability from chronic diseases cost the world's economy $\$ 200$ billion in 2018, with sick leave and preterm births costing $\$ 100$ billion and $\$ 90$ billion respectively. The total annual cost of air pollution in China is estimated to be $\$ 900$ billion each year with costs in the U.S. running to $\$ 600$ billion annually. Indian cities have scored unfavorably in air pollution indexes for years and the issue costs the country $\$ 150$ billion per year on average. In 2018 , the cost of dirty air equated to 6.6 percent of Chinese GDP, 5.4 percent of India's GDP and 3 percent of U.S. GDP. ${ }^{7}$ 


\section{The Economic Burden Of Air Pollution}

Economic costs of air pollution from fossil fuels as a share of GDP in 2018

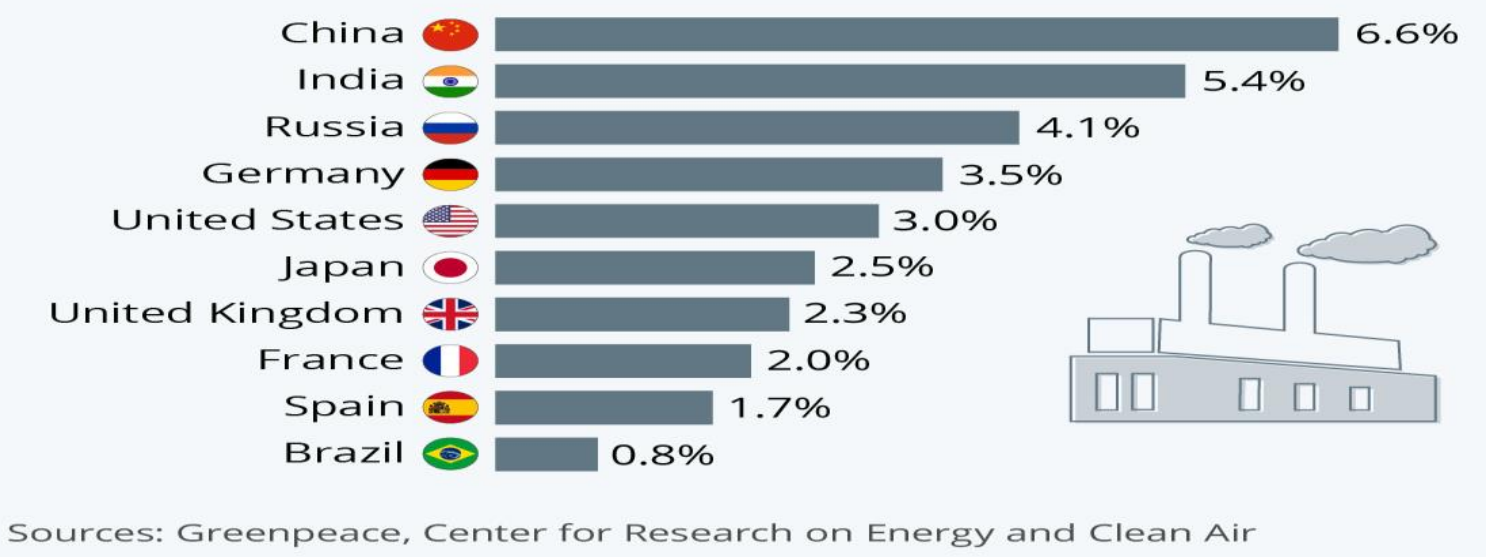

(c) $\odot \ominus$

7“"This is the global economic cost of air pollution",

https://www.weforum.org/agenda/2020/02/the-economic-burden-of-air-pollution/

This table shows the damage due to particulate emissions as a percentage of gross national income in some countries of the world. 
ISSN 2661-2666 (Online) International Scientific Journal Monte (ISJM) DOI: 10.33807/monte.202004661 Volume 2. No. 1 (2019): April

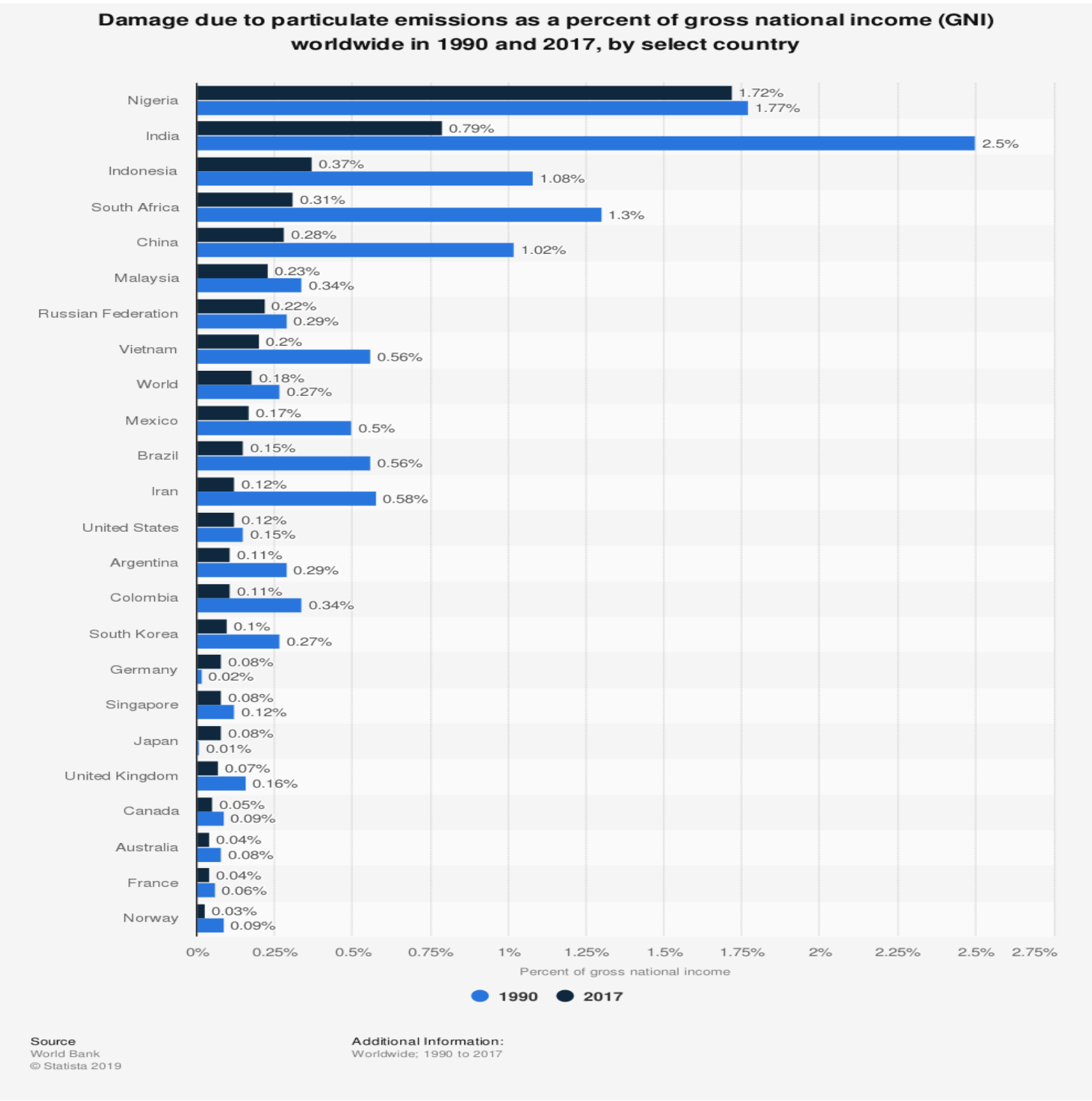

\section{Source: Statista.com}

While pollution-related deaths strike mainly young children and the elderly, premature deaths also result in lost labor income for working-age men and women. The report finds that annual labor income losses cost the equivalent of almost 1 percent - 0.83 percent -- of Gross Domestic Product (GDP) in South Asia. In East Asia and the Pacific, where the population is ageing, labor income losses represent 0.25 percent of GDP, while in SubSaharan Africa, where air pollution impairs the earning potential of younger populations, annual labor income losses represent the equivalent of 0.61 percent of GDP.

When looking at fatalities across all age groups through the lens of "welfare losses", an approach commonly used to evaluate the costs and benefits of environmental regulations in a given country context, the aggregate cost of premature deaths was more than US\$5 trillion worldwide in 2013. In East and South Asia, welfare losses related to air pollution were the equivalent of about 7.5 percent of GDP. ${ }^{8}$

In 2011 air pollution from the energy industry cost the U.S economy \$131 billion in "social damages" according to one study. Most of this was in the form of health care costs for people who became sick from air pollution. As staggering as it may seem, the cost in 2011 was actually lower than in 2002 when social costs tallied \$175 billion. 
The decline has been attributed to the effectiveness of more stringent emissions regulations and points to the need to continue in this direction.

Air pollution has some indirect costs, too, including unexpected impacts to school and work performance. A study found that the productivity of pear packers in Northern California was measurably lowered by air pollution. Another study found that Chinese call center workers take more breaks on high pollution days. A third study found that there were more absences in Texas school districts as a result of high carbon monoxide levels.

Air pollution knows no borders and can wreak havoc with climate and weather. For example, pollution from_Asia's manufacturing industries has reached the United States. This particularly affects the western part of the United States. It could also lead to more powerful storms over the Pacific Ocean. ${ }^{9}$

8“Air Pollution Deaths Cost Global Economy US\$225 Billion”,

https://www.worldbank.org/en/news/press-release/2016/09/08/air-pollution-deaths-cost-global-economy-225$\underline{\text { billion }}$

966Air Pollution Causes, Effects, and Solutions",

https://www.thebalance.com/air-pollution-causes-effects-solutions-4775825

While air pollution can have serious effects on your health, it can also impact your wallet. With the increased need for health care comes the potential for increased costs of health insurance and out-of-pocket expenses.

According to a study by the RAND Corporation, 30,000 people were admitted to the hospital or emergency room between 2005 and 2007 for asthma, respiratory, and cardiovascular issues related to California's air quality. The study found that three-fourths of the cases could be attributed to high ambient levels of fine particulate matter, while the rest were related to high ozone levels. As a result of these hospitalizations, the public and private health insurance companies — and thus the employers and employees — ultimately paid about \$193 million for the care.

This study is just an example of the financial costs that can come from the health effects of air pollution. On a larger scale, pollution-related health care costs could increase individuals' health insurance premiums and out-ofpocket expenses for drugs and services associated with these effects, such as respiratory issues like asthma. And, depending on the type of plan, such as one with a high deductible, the costs to manage these health effects with medicine, inhalers, and more could be higher. While many individual factors into play with the true cost of air pollution, it may still be smart to consider how health risks can pose a threat to your financial situation. Understanding how to prevent the health effects of air pollution could help you save money in the future. ${ }^{10}$

Even before the point of death, even in cases of illness, where it appears as though accountants and economists are considering the same costs, they are not counting the same thing, but rather addressing two features of the same reality. Consider, for example, a night's hospital stays on the part of a given patient. The financial cost may be found in, inter alia, the attributable part of the wages paid to the relevant medical staff, the attributable part of the bills paid to the relevant suppliers of equipment, energy, materials, and so on. In contrast, the economic cost is the sacrifice of value by the individual patient and, if relevant, the patient's household. This entails the sacrifice of consumption as a result of the wages foregone, the sacrifice of leisure as a result of the free time foregone, and so on. There are different calculations at work: they are not interchangeable, nor can their results be added up.

Similar considerations apply to the impact on the national accounts of air pollution or any other health risk factor. The premature deaths of working-age people will have an impact on the national accounts through the loss of labor inputs to production and the outputs of it. Those responsible for measuring, analyzing and forecasting changes in gross domestic product (GDP) will have an interest in measuring this impact. ${ }^{11}$

10“'Health Effects of Air Pollution",

https://www.thebalance.com/health-effects-of-air-pollution-4772278

11"Economic cost of the health impact of air pollution in Europe", 
ISSN 2661-2666 (Online) International Scientific Journal Monte (ISJM) DOI: 10.33807/monte.202004661

Volume 2. No. 1 (2019): April

http://www.euro.who.int/_data/assets/pdf_file/0004/276772/Economic-cost-health-impact-air-pollution-en.pdf

\section{Conclusions}

Environmental pollution, or more precisely environmental air, has been found to have very negative effects on the health of the population, ecosystems and the economies of countries around the world in general.

Environmental pollution is getting worse day by day in different parts of the world, exceeding the established pollution limits, the excesses of which severely damage human health but are sometimes also life threatening and fatal.

According to the Protocols of the World Health Organization, certain diseases are associated with environmental pollution, such as diseases of the respiratory system: asthma, emphysema, acute bronchitis, chronic obstructive pulmonary disease, cardiovascular disease and stroke.

In this regard, it should be considered that from the impact that pollution has on health, namely the increase of diseases, the increased attendance of patients in health centers for treatment also increases the cost of health care, which means that a significant part of the state budget is allocated for this.

This also includes premature deaths from environmental pollution that reduces productivity in general, obtaining medical leave from employees during periods of pollution that reduce working hours also loses efficiency at work and burdens the budget of the health fund.

Therefore, the governments of the states should have long-term plans to reduce environmental pollution with special emphasis on environmental air pollution and thus in some way reduce the costs of environmental pollution and the means of financial means dedicated to the fight against pollution to direct them to a better and healthier life for the citizens. 
ISSN 2661-2666 (Online) International Scientific Journal Monte (ISJM) DOI: 10.33807/monte.202004661

Volume 2. No. 1 (2019): April

\section{References}

OECD Publishing (n.d). The economic consequences of outdoor air pollution. Retrieved from: https://read.oecdilibrary.org/environment/the-economic-consequences-of-outdoor-air-pollution_9789264257474en\#page20

UNECE (n.d). Air pollution and economic development, The United Nations Economic Commission for Europe. Retrieved from: https://www.unece.org/environmental-policy/conventions/envlrtapwelcome/crosssectoral-linkages/air-pollution-and-economic-development.html

OECD (n.d). The economic cost of air pollution: Evidence from Europe. Retrieved from: https://www.oecdilibrary.org/docserver/56119490en.pdf?expires $=1587927668 \& \mathrm{id}=\mathrm{id} \&$ accname $=$ guest $\&$ checksum $=470 \mathrm{CEB} 7142676 \mathrm{~B} 44 \mathrm{CD} 4 \mathrm{~B} 93224 \mathrm{~F}$ $\underline{604411}$

McCarthy, N. (2020). This is the global economic cost of air pollution. World Economic Forum. Retrieved from: https://www.weforum.org/agenda/2020/02/the-economic-burden-of-air-pollution/

The World Bank (2016). Air Pollution Deaths Cost Global Economy US\$225 Billion. Retrieved from: https://www.worldbank.org/en/news/press-release/2016/09/08/air-pollution-deaths-cost-globaleconomy-225-billion

Amadeo, K. (2020). Air Pollution Causes, Effects, and Solutions. Retrieved from: https://www.thebalance.com/air-pollution-causes-effects-solutions-4775825

Hunt, J. (2020). Health Effects of Air Pollution. Retrieved from: https://www.thebalance.com/health-effects-ofair-pollution-4772278

World Health Organization (2015). Economic cost of the health impact of air pollution in Europe. Retrieved from: http://www.euro.who.int/_data/assets/pdf_file/0004/276772/Economic-cost-health-impact-airpollution-en.pdf 